\title{
POLIFUNCTIONAL ADDITIVES TO FUEL AND LUBRICANTS
}

(C) O.V. Trotsenko, A.B. Grigorov, Doctor of Technical Sciences, V.M. Nazarov, PhD in technical sciences (National Technical University "Kharkiv Polytechnic Institute", 61002, Kharkiv, Kirpicheva st., 2, Ukraine), O.V. Zharova (State Enterprise "Ukrainian State Research Institute for Carbochemistry (UKHIN)", 61023, Kharkov, Vesnina st., 7, Ukraine)

The article considers the possibility of increasing the level of operation properties of fuels and lubricants through the use of multifunctional additives. Taking into account the cost of additives, the conditions of their use and the wide range of properties they provide to fuels and lubricants, this path can be considered the most promising in comparison with the purchase of quality crude oil and total re-equipment of existing production. It is proposed to classify polyfunctional additives for fuels and lubricants according to the properties they exhibit and the degree of these properties. Such classification allows to select of a balanced package of additives for fuels and lubricants, to increase their production (on average, the package of additives is about $10 \% \mathrm{wt}$.) and to reduce the cost of the product.

In order to control and optimize the circulation of fuels and lubricants and to prevent their falsification (especially in the production of branded grades of the premium class fuels and lubricants), it is proposed to use colorants, which due to their properties can be considered as multifunctional additives / components. Among all the substances on the basis of which industrial colorants of general purpose are produced now, azodyes are the most promising. This is primarily due to the wide range of properties of these substances: antioxidant, biocidal, detergentdispersant, protective, anti-wear. Based on the analysis of information about the use of colorants in fuels and lubricants, to expand the existing range of such additives is possible through the diazocompounds. These substances have a stable color, which, depending on the structure of the compound, ranges from yellow to purple-red. It is shown in the article, that diue to the properties of the class of azocompounds, some of these substances can be considered as promising multifunctional additives in the production of fuels and lubricants.

Keywords: fuels and lubricants, additives, multifunctional properties, classification, colorants, azodyes.

Corresponding author O.V. Trotsenko,e-mail: trocenko.alexandr@gmail.com 